\title{
Gym exclusively for overweight people comes to Canada
}

A

$\mathrm{n}$ American chain of gyms that accepts only members with at least 50 pounds to lose has opened its first location in Canada. The chain, Downsize Fitness, aims to create a welcoming, stigma-free, communitybased environment for people who feel intimidated by mainstream gyms.

"We focus on functional fitness," says Kishan Shah, president of Downsize Fitness, which also has locations in Illinois and Texas. "Most people are concerned with, 'Can I get up off the floor? Can I bend down and touch the floor? Can I fit into an airplane seat without a seat belt extender? Can I keep up with my kids?' They don't want to look like bodybuilders."

Promoting extreme weight loss is not the focus at the Canadian gym in Orléans, Ontario. "It's based on getting people healthy, and one of the side effects is weight loss," says Martin Charron, a manager at the new gym.

Three of the four managers at the Orléans gym have themselves lost a considerable weight, and remember how uncomfortable they used to feel in traditional gyms.

"You go to the gym to get in shape. You don't lose the weight first so that you walk into the gym and look like everybody else," says Marc Robert, another manager at the gym.

One major difference between Downsize Fitness and traditional gyms is an emphasis on community. For people hoping to lose 50 pounds or more, and keep it off, a supportive community is essential, according to Downsize managers. The gym hopes to build community through group fitness classes, regular check-ins and social media.

"We encourage members to hang out together, to exchange numbers, go for coffee," says Robert.

Another factor that can discourage fitness novices in the gym is a lack of knowledge about how to perform exercises. Downsize Fitness offers modifiable exercise programs with various levels of difficulty, and avoids the dreaded drill sergeant approach.

"We make sure that our fitness pro-

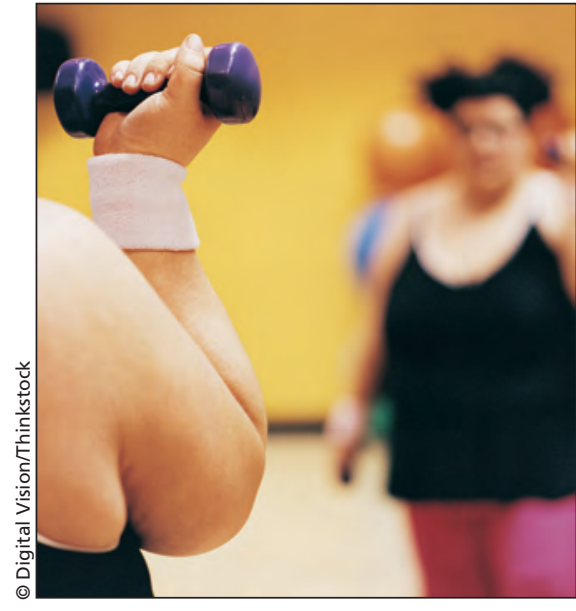

People who are overweight often feel intimidated or judged in traditional gyms.

gramming is designed so the newbie that just walked into the door feels extremely comfortable," says Shah.

Several other companies in Canada also offer fitness services exclusively to overweight patrons, including Fit Zone Plus in Toronto, Ontario, and Body Exchange, which has several locations in British Columbia.

The burgeoning number of these facilities may be due to the stigma that people who are overweight or obese experience at traditional gyms. As Lindy West describes it, "It's entering a building where you know that every person inside is working toward the singular goal of not becoming you."

On the message boards for the fitness website MyFitnessPal, many people discuss being afraid to run outside or attend a gym.

These fears often start early in life. Many overweight youth shy away from sports or other forms of exercise in public, according to a recent review of 15 qualitative studies on barriers to physical activity among overweight and obese adolescents. One of those barriers was the feeling these teens had that their bodies were on display during physical activity or in the change room, making them less likely to actively participate in gym classes. - Catherine Cross, CMAJ

CMAJ 2014. DOI:10.1503/cmaj.109-4682 